\title{
A Compact and Portable Deposition Chamber to Study Nanoparticles in Air-Exposed Tissue
}

\author{
Peter Mertes, MSc, ${ }^{1}$ Arnaud P. Praplan, MSc, Lisa Künzi, MSc, ${ }^{2}$ Josef Dommen, PhD, \\ Urs Baltensperger, PhD, ${ }^{1}$ Marianne Geiser, PhD, ${ }^{2}$ Ernest Weingartner, $\mathrm{PhD}$, Jaroslav Ricka, PhD, ${ }^{3}$ \\ Martin Fierz, $\mathrm{PhD}{ }^{4}$ and Markus Kalberer, $\mathrm{PhD}^{5}$
}

\begin{abstract}
Background: Epidemiological studies show that elevated levels of particulate matter in ambient air are highly correlated with respiratory and cardiovascular diseases. Atmospheric particles originate from a large number of sources and have a highly complex and variable composition. An assessment of their potential health risks and the identification of the most toxic particle sources would require a large number of investigations. Due to ethical and economic reasons, it is desirable to reduce the number of in vivo studies and to develop suitable in vitro systems for the investigation of cell-particle interactions.

Methods: We present the design of a new particle deposition chamber in which aerosol particles are deposited onto cell cultures out of a continuous air flow. The chamber allows for a simultaneous exposure of 12 cell cultures.

Results: Physiological conditions within the deposition chamber can be sustained constantly at $36-37^{\circ} \mathrm{C}$ and $90-$ $95 \%$ relative humidity. Particle deposition within the chamber and especially on the cell cultures was determined in detail, showing that during a deposition time of $2 \mathrm{hr} 8.4 \%$ ( $24 \%$ relative standard deviation) of particles with a mean diameter of $50 \mathrm{~nm}$ [mass median diameter of $100 \mathrm{~nm}$ (geometric standard deviation 1.7)] are deposited on the cell cultures, which is equal to $24-34 \%$ of all charged particles. The average well-to-well variability of particles deposited simultaneously in the 12 cell cultures during an experiment is $15.6 \%$ ( $24.7 \%$ relative standard deviation). Conclusions: This particle deposition chamber is a new in vitro system to investigate realistic cell-particle interactions at physiological conditions, minimizing stress on the cell cultures other than from deposited particles. A detailed knowledge of particle deposition characteristics on the cell cultures allows evaluating reliable dose-response relationships. The compact and portable design of the deposition chamber allows for measurements at any particle sources of interest.
\end{abstract}

Key words: ultrafine particles, particle-cell interaction, aerosol, particle deposition, in vitro toxicology

\section{Introduction}

A EROSOL PARTICLES present in the ambient atmosphere and engineered nanoparticles used in industrial processes and consumer products are potentially involved in a number of respiratory and cardiovascular diseases. The main route of undesired uptake of submicrometer particles into the body is via inhalation. ${ }^{(1)}$ Epidemiological studies provide ample and consistent evidence for a link between adverse health effects and increased concentrations of ambient particles. ${ }^{(2-4)}$ There are indications for a specific toxicological role of ultrafine or nanoparticles, i.e., particles with diameters of $<100 \mathrm{~nm} .^{(5-7)}$ Health effects assumed to be associated with aerosol particles are one of the major environmental public health issues in industrialized countries, especially as the environmental burden of nanoparticles is likely to increase in the future. ${ }^{(8)}$

Besides atmospheric particles, a large number of engineered nanoparticles are being introduced in industrial

\footnotetext{
${ }^{1}$ Laboratory of Atmospheric Chemistry, Paul Scherrer Institute, 5232 Villigen, Switzerland.

${ }^{2}$ Institute of Anatomy, University of Bern, 3012 Bern, Switzerland.

${ }^{3}$ Institute of Applied Physics, University of Bern, 3012 Bern, Switzerland.

${ }^{4}$ University of Applied Science Northwestern Switzerland, 5210 Windisch, Switzerland.

${ }^{5}$ Department of Chemistry, University of Cambridge, Cambridge CB2 1EW, United Kingdom.
} 
processes, many of them containing potentially toxic metals. These engineered nanoparticles may become aerosolized at some stage of their life cycle and pose additional health risks for specific workplace settings, but also for the general public. ${ }^{(9)}$ It should be noted that real-life release mechanisms may strongly alter the size distribution of such engineered nanoparticles, and as a result of this they might not be present in the atmosphere as nanometer-size particles or have altered physical-chemical properties.

Mechanistic in vivo animal and in vitro studies support the findings of epidemiological studies, ${ }^{(10-12)}$ but the current understanding on a cellular or biochemical level is still incomplete. Thus, a thorough understanding of (nano)particlelung interactions is urgently needed. In addition, an increasing use of aerosol particles for pharmaceutical drug delivery requires a detailed understanding of particle deposition and drug uptake processes via the lung.

Increasing diversity of engineered nanoparticles, pharmaceutical aerosol drug delivery systems, and also the large number of sources of atmospheric particles call for comprehensive investigations of particle-lung interactions. But an extensive use of animal models is hampered by ethical, technical, and economic reasons, and therefore in vitro techniques are strongly favored. A realistic experimental setup to assess aerosol particle-lung interactions and associated potential toxic effects with in vitro studies should include the following essential parts: (1) (nano)particles need to be deposited onto the cell cultures as real aerosol particles, i.e., from a continuous air flow at realistic particle concentrations, composition, and size; (2) cell cultures used to assess nanoparticle effects need to closely mimic the complex multicell structure of the human lungs ${ }^{(13,14)}$; and (3) the exposure and deposition scenario should mimic the corresponding processes in the lungs as accurately as possible.

Current experimental procedures for in vitro particle studies rarely meet these essential requirements, which might result in severe biases when interactions between particles and lung cells are interpreted. Particles are often deposited onto lung cells all at once (e.g., pipetted). This does not reflect the extended period of time during which particles are usually deposited on the lung surface and results in often unrealistically high particle concentrations in in vitro studies. In addition, suspending particles in a solvent can substantially alter their chemical and physical properties compared with conditions where they are freely suspended in air. ${ }^{(13,14)}$

We present here a new instrument, which aims to mimic (nano)particle deposition and interaction with lung cells in in vitro experiments as accurately as possible compared with conditions in the lung. A first version of our exposure system introduced the concept of electrostatic deposition of bipolarly charged aerosol particles onto lung cell cultures from a continuous air flow, which is much more efficient than diffusional deposition. ${ }^{(15)}$ Further, we demonstrated that the associated very weak currents did not induce any cell effects. We also showed that the particles were evenly deposited onto the cell cultures, an essential aspect when toxicological dose-effect relationships are established. Particles were humidified [to $>80 \%$ relative humidity $(\mathrm{RH})$ ] and heated to $36-37^{\circ} \mathrm{C}$ outside of the deposition chamber to mimic incubator-like conditions.

In the significantly improved in vitro system described here, the realistic particle deposition is further refined.
Essential parts of the experimental setup, i.e., aerosol humidification, heating, and cell exposure, are combined into one portable instrument, which allows performing experiments outside the cell biology laboratory at any particle source of interest. Besides a detailed description of design and operation of the new deposition chamber, the deposition efficiency of particles is evaluated in detail. This is an essential aspect if biological responses are interpreted in a toxicological context.

\section{Materials and Methods}

\section{Design of the deposition chamber}

A schematic of the deposition chamber is shown in Figure 1. The instrument consists of three subunits: a humidifier, a distributor, and a cell chamber unit. Immediately after entering the deposition chamber, the aerosol is humidified by passing through a GORE-TEX ${ }^{\circledR}$ tube (length, $10 \mathrm{~cm}$; inner diameter, $0.6 \mathrm{~cm})$ that is immersed in a heated water bath $(1.5$ $\mathrm{L}, 18 \mathrm{M} \Omega \mathrm{cm}$ water). Thus, the aerosol flow is conditioned to $36-37^{\circ} \mathrm{C}$ and $90-95 \% \mathrm{RH}$. In the distributor, the aerosol is evenly divided into 12 circularly arranged delivery tubes (inner diameter, $1 \mathrm{~cm}$ ). When exiting the delivery tubes, the aerosol passes over the cell cultures grown on filter inserts [polyester membrane, $0.4 \mu \mathrm{m}$ pore size; $24-\mathrm{mm}$ Transwell $^{\circledR}$ inserts (Corning, Vitaris, Baar, Switzerland) or 24-mm Falcon $^{\circledR}$ inserts (Becton Dickinson AG, Milian, Geneva, Switzerland)] positioned approximately $2 \mathrm{~mm}$ below each tube. The filter inserts are placed in a home-built 12-well plate (for the simultaneous exposure of 12 cell cultures), which is routinely autoclaved before each cell culture exposure experiment. All other parts of the deposition chamber, except the short GORE-TEX tube, can also be sterilized, if required. The air is pumped out of the chamber through a centrally positioned outlet, which is connected to a membrane pump. Total air flow rate is $600 \mathrm{~mL} \mathrm{~min}^{-1}$, i.e., $50 \mathrm{~mL} \mathrm{~min}^{-1}$ in each

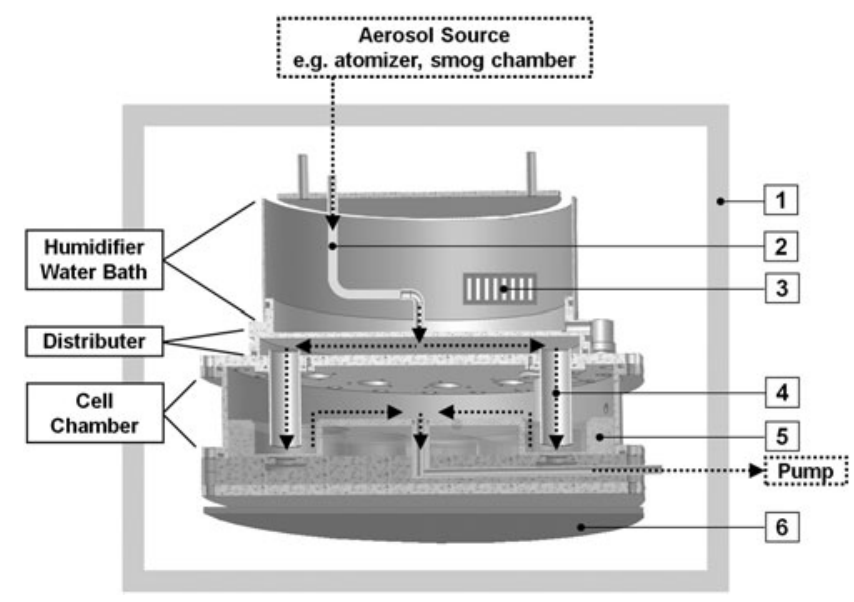

FIG. 1. Design of the deposition chamber. The aerosol particle deposition chamber consists of a cylindrical humidifier, a distributor, and the cell chamber containing the 12well plate (5) and the delivery tubes (4) (see also Fig. 2a). The chamber is heated in the water bath (3) as well as at the bottom (6). The device is insulated by a polystyrene housing (1). The continuous air flow from the aerosol source is humidified by passing through a GORE-TEX tube (2). The flow path of the aerosol is illustrated by the blue arrows. 
delivery tube. The deposition chamber is heated by a $120 \mathrm{~W}$ resistor in the humidifier's water bath, as well as a $6.2 \mathrm{~W}$ silicone rubber thermofoil at the bottom of the chamber. An insulating polystyrene housing ( $4 \mathrm{~cm}$ thickness) around the entire deposition chamber assures temperature homogeneity within the instrument. Each of the 12 delivery tubes is equipped with lead-throughs to allow for installation of optical fibers to detect ciliary beat frequency online during the particle exposure, as described in detail by Savi and coworkers. ${ }^{(15)}$ Potentially, also other optical signals, e.g., from fluorescent markers, could be observed online with these optical fibers. The radial design of the entire instrument assures an even distribution of the particles to the 12 cell culture wells.

Before entering the deposition chamber, trace gases that are potentially present in the aerosol (such as nitrogen oxides, ozone, and volatile organic compounds) are removed by a charcoal denuder to assure that observed biological effects are due only to particles. Five percent $\mathrm{CO}_{2}$ (by volume) is added to the aerosol flow to maintain the cell culture medium in the physiological $\mathrm{pH}$ range. Particles then pass a ${ }^{85} \mathrm{Kr}$ bipolar charger $(185 \mathrm{MBq})$, which assures that the aerosol particles are in charge equilibrium when they enter the deposition chamber. After passing the bipolar charger, particles carry 1-2 elemental charges (positive or negative), which is very similar to the particle charge equilibrium in the atmosphere. ${ }^{(15)}$ This charge results in a very low current deposited on the cell culture, typically in the sub-femtoampere range, as discussed in detail by Savi et al., ${ }^{(15)}$ and is not expected to affect the cell cultures. Inside the deposition chamber in the cell chamber unit, the charged particles are deposited evenly (as discussed in detail by Savi et al. ${ }^{(15)}$ ) and efficiently onto the cell cultures by applying an alternating square-wave electrical field of $4 \mathrm{kV} \mathrm{cm}^{-1}$ between an electrode below each well (diameter, $1.8 \mathrm{~cm}$ ) and a fine metal mesh at the outlet of each delivery tube as counter electrode (diameter, $1.2 \mathrm{~cm}$ ). To avoid particle losses, only stainless steel or conductive rubber tubing is used.

\section{Particle generation}

A thorough characterization of the deposition efficiency of particles (i.e., the fraction of particles deposited out of the aerosol flow) is essential to assess how many particles are deposited on the cell cultures during an exposure experiment. Only a precise knowledge of the particle deposition efficiency allows the establishing of particle dose-cell effect relationships, the ultimate goal of many toxicological particle-lung interaction studies.

For the deposition characterization experiments, adipic acid aerosol particles were produced using a conventional recirculation atomizer (model 3076, TSI, Shoreview, MN) connected to a filtered air supply (model 3074, TSI). Adipic acid particles were used for these experiments, because this compound has favorable physical-chemical properties (see below) and the size of the particles is representative of particles found in the ambient atmosphere. The inlet air pressure for the atomizer was set to about 3 bar and the outlet flow was $2.1 \mathrm{~L} \mathrm{~min}^{-1}$. We kept the adipic acid concentration within the nebulizer constant by using a large volume $(1 \mathrm{~L})$ of the solution. The aerosol generator produced a stable aerosol, which was checked by performing repetitive size distribution measurements, before and after every experiment. Three ${ }^{85} \mathrm{Kr}$ sources placed after the atomizer $(2 \times 74 \mathrm{MBq}, 1 \times 185 \mathrm{MBq})$ were used to assure that the atomized particles are in charge equilibrium. An aqueous solution $\left(170 \mu \mathrm{mol} \mathrm{L}{ }^{-1}\right)$ of adipic acid [hexanedioic acid: HOOC- $\left(\mathrm{CH}_{2}\right)_{4}-\mathrm{COOH}$ ] was atomized for these measurements, generating particles with a diameter mode of $50 \mathrm{~nm}$ (number-weighted particle size distribution). The mass-weighted mode was at about $100 \mathrm{~nm}$. Typical concentrations were $7-8 \times 10^{5}$ particles $\mathrm{cm}^{-3}$ with a polydisperse size distribution (sigma 1.7). Adipic acid has a very high deliquescence point $(\sim 100 \% \mathrm{RH})$, and therefore the $\mathrm{RH}$ of $90-95 \%$ in the chamber does not affect the size distribution of adipic acid particles. ${ }^{(16)}$ The low vapor pressure of adipic acid (about $9.8 \times 10^{-6} \mathrm{~Pa}$ at $\left.296 \mathrm{~K}\right)^{(17)}$ assures that no adipic acid evaporates after deposition. Particle number size distributions between 15 and $760 \mathrm{~nm}$ were measured with a scanning mobility particle sizer (SMPS) consisting of an electrostatic classifier [differential mobility analyzer (DMA) model 3071A, TSI] and a condensation particle counter (CPC model 3022A, TSI). The sheath air flow rate was $3 \mathrm{~L} \mathrm{~min}^{-1}$ and the sampled air flow rate $0.3 \mathrm{~L} \mathrm{~min}^{-1}$. One scan took $3 \mathrm{~min}$.

As the particle deposition efficiency is related to the total amount of adipic acid particles entering the deposition chamber in every experiment, a filter (Millipore FSW04700 Fluoropore PTFE $3 \mu \mathrm{m}$ ) sample of the total aerosol flow was taken before and after each deposition experiment. At a flow rate of $600 \mathrm{~mL} \mathrm{~min}^{-1}$, a filter sample of the nebulized aerosol was collected during $15 \mathrm{~min}$ (total aerosol volume collected: 9 L). The filter was positioned upstream of the deposition chamber. The filter was extracted in $2 \mathrm{~mL}$ of $0.05 \mathrm{mM} \mathrm{NaOH}$ solution, and the extract was then diluted by a factor of 10 . This solution was analyzed with ion chromatography coupled to a mass spectrometer (IC/MS) like all other samples. From the measured mass of adipic acid per milliliter, we calculated the mass of adipic acid per cubic meter of air. The comparison of IC/MS and SMPS measurements resulted in an effective density for adipic acid of $0.5 \mathrm{~g} \mathrm{~cm}^{-3}$, which was used to convert the SMPS volume data into mass concentrations.

\section{IC/MS analysis}

For a detailed quantification of the particles deposited on the cell culture inserts and to assess the variability of the deposition between the twelve inserts, the following chemical analysis method was developed: The adipic acid mass deposited by the particles in the deposition chamber was quantified with IC/MS. Particles were deposited in the deposition chamber as in normal operation, except that the filter membranes of the inserts (on which the cell cultures are normally grown) were removed. The 12 wells were filled with $3 \mathrm{~mL}$ of an aqueous sodium hydroxide $(\mathrm{NaOH})$ solution up to the height where the filter membrane of the insert would be located (see Fig. 2a). The solution had a pH of 9-10 $(0.05 \mathrm{mM})$, such that dissolved adipic acid deprotonates and cannot evaporate. The aerosol flow in these deposition experiments was $50 \mathrm{~mL} \mathrm{~min}{ }^{-1}$ in each particle delivery tube $\left(600 \mathrm{~mL} \mathrm{~min}^{-1}\right.$ in total), and the exposure time was $120 \mathrm{~min}$. Three different settings were considered, as described in Figure 2b: bypassing the entire deposition chamber (1) and passing the aerosol through the deposition chamber with the electrical field off (2) or on (3).

Particle deposition on the fine metal meshes at the end of each particle delivery tube (i.e., at the counter electrode) was 


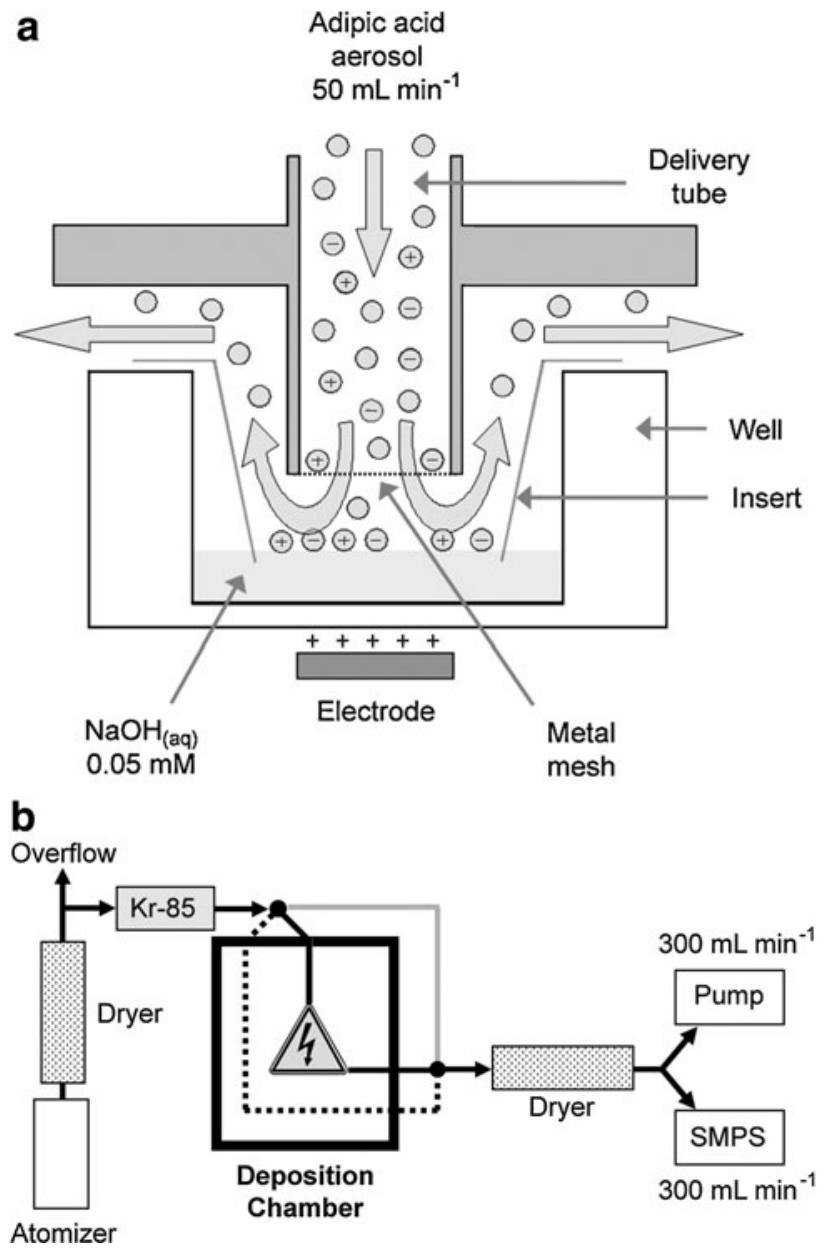

FIG. 2. Experimental setup of particle deposition efficiency measurements. (a) Schematic of experimental setup used to quantify particle deposition in the wells and the particle delivery tubes. Deposited particles were quantified with IC/ MS. (b) Three different settings of the aerosol flow were used to quantify the overall particle deposition in the chamber using an SMPS: (1) bypassing the deposition chamber (total aerosol particle number, gray line); (2) passing the aerosol through the deposition chamber without electrical field (dotted line); and (3) passing the aerosol through the deposition chamber with electrical field on (black line).

also quantified. Adipic acid particles were dissolved from the meshes by immersing the ends of the delivery tubes for $5 \mathrm{~min}$ in aqueous $\mathrm{NaOH}$ solution $(2 \mathrm{~mL}, \mathrm{pH} 9-10)$ filled into each well of a separate 12-well plate.

The adipic acid concentration in the $\mathrm{NaOH}$ solutions was then quantified with IC/MS using a guard column (AG11HC, Dionex, Sunnyvale, CA) and an analytical column (AS11-HC, Dionex). The eluent (flow rate, $0.35 \mathrm{~mL} \mathrm{~min}^{-1}$ ) consisted of an $\mathrm{OH}^{-}$gradient $\left(0 \mathrm{~min}, 0.95 \mathrm{mM} \mathrm{OH}{ }^{-} ; 5 \mathrm{~min}\right.$, $0.95 \mathrm{mM} \mathrm{OH}^{-}$; $15 \mathrm{~min}, 15 \mathrm{mM} \mathrm{OH}^{-}$; $21 \mathrm{~min}, 60 \mathrm{mM} \mathrm{OH}^{-}$; $23 \mathrm{~min}, 60 \mathrm{mM} \mathrm{OH}^{-}$; $23.1 \mathrm{~min}, 0.5 \mathrm{mM} \mathrm{OH}^{-}$; $29 \mathrm{~min}, 0.5 \mathrm{mM}$ $\mathrm{OH}^{-}$). The gradient was generated online by an Eluent Generator (EG40, Dionex) from an EluGen potassium hydroxide cartridge (EGC-KOH, Dionex) and ultrapure water $(18 \mathrm{M} \Omega \mathrm{cm})$. After the analytical column, $\mathrm{OH}^{-}$anions were suppressed by an anion self-regenerating suppressor (ASRS $3002 \mathrm{~mm}$, Dionex). A conductivity detector and a quadru- pole mass spectrometer with unity mass resolution were used as detectors. The IC/MS instrument was calibrated by direct injection of aqueous adipic acid standards (1.103, 10.95 , and $109.6 \mathrm{ng} \mathrm{mL}^{-1}$; corresponding to $7.5,75$, and $750 \mathrm{nM}$ ), and a first-order least-squares regression was fitted to the data. The retention time of adipic acid was $19.9 \mathrm{~min}$. The reproducibility of this method is $3.6 \%$, which is the standard deviation of three measurements of a $75 \mathrm{nM}$ adipic acid standard solution [i.e., within the concentration range of our analyzed samples (20-200 nM)]. Samples were injected via a $100-\mu \mathrm{L}$ sample loop without preconcentration step. The comparison of IC/MS and SMPS measurements resulted in an effective density of adipic acid in the particles of $0.5 \mathrm{~g} \mathrm{~cm}^{-3}$. Although the density of solid adipic acid in the bulk phase is $1.36 \mathrm{~g} \mathrm{~cm}^{-3}$, atomization and subsequent drying may lead to fragmented particles with a low effective density.

\section{Results and Discussion}

\section{Chamber operation}

The 12-well plate containing the cell culture inserts is easily inserted into the deposition chamber by opening the bottom plate of the cell chamber (see Fig. 1). The insulating polystyrene enclosure assures that a homogeneous temperature and humidity are established quickly in the deposition chamber after closing, as shown in Figure 3. The chamber was first brought from room temperature to the set temperature of $37^{\circ} \mathrm{C}$, which takes about $2 \mathrm{hr}$ (Fig. 3, data at times before exposure start). Then the chamber was opened for about $4 \mathrm{~min}$, which is enough to exchange the cell cultures, and closed again. The fast recovery of the desired temperature and humidity prevents condensation of water within the chamber at high RH, which is crucial to avoid particle losses, as well as temperature and humidity-induced stress for the cells. Seventeen minutes after the chamber is closed, the temperature reaches $35^{\circ} \mathrm{C}$ and $\mathrm{RH}$ exceeds $85 \%$ (Fig. 3); after $30 \mathrm{~min}$, the temperature stays constant between $36^{\circ} \mathrm{C}$ and $37^{\circ} \mathrm{C}$ and $\mathrm{RH}$ between $90 \%$ and $95 \%$, which allows the

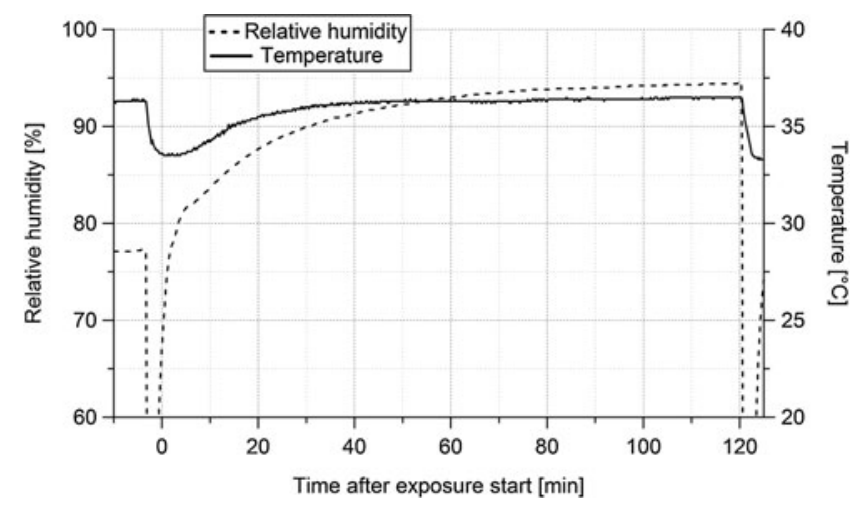

FIG. 3. Temporal evolution of temperature and RH during exposure. After the deposition chamber is opened to replace a 12-well plate, the temperature and $\mathrm{RH}$ recover rapidly, i.e., after $17 \mathrm{~min}$, temperature reaches $35^{\circ} \mathrm{C}$ and $\mathrm{RH}$ exceeds $85 \%$. After $30 \mathrm{~min}$, temperature is between $36^{\circ} \mathrm{C}$ and $37^{\circ} \mathrm{C}$ and $\mathrm{RH}$ between $90 \%$ and $95 \%$, assuring optimal conditions for the cell cultures. The deposition chamber was preconditioned, and the replacement of a well plate typically takes about $4 \mathrm{~min}$. 
performance of cell exposure experiments for several hours. This mimics physiological conditions in the airways very well, and hence stress factors on the cells other than induced by aerosol particles are minimized. ${ }^{(18)}$ After a typical exposure time of a few hours, the 12-well plate is removed from the deposition chamber for further analysis of the cell cultures.

In two recent studies, the deposition chamber was used to expose various lung cell cultures to aerosol particles from diesel exhaust, wood burning, and secondary organic aerosols. These experiments and the observed biological effects are described by Gaschen and co-workers. ${ }^{(19)}$

\section{Particle deposition characteristics}

Overall particle losses in the deposition chamber. The fraction of adipic acid particles (generated online with a nebulizer) deposited within the entire deposition chamber, with and without electrical field, was determined using an SMPS. The experimental setup is shown in Figure $2 \mathrm{~b}$. Three different experiments were performed: bypassing the deposition chamber (1) and passing the aerosol through the deposition chamber with the electrical field off (2) and on (3). This setup allows the effect of the electrostatic deposition to be determined and the overall diffusional losses in the entire deposition chamber to be quantified.

Figure $4 \mathrm{a}$ shows the number-weighted particle size distribution of adipic acid aerosol particles for the three different measurement conditions described in Figure 2b: bypassing the chamber (black) and passing through the deposition chamber with the electrical field off (light gray) and with the electrical field on (gray). A significant fraction of the particles is lost in the deposition chamber even when the electrical field is off, as illustrated by the difference between the black (bypass mode) and light gray (electrical field off) distributions. An increasing fraction of particles is lost without electrical field between $30 \mathrm{~nm}$ and $50 \mathrm{~nm}$, which is likely due to turbulence effects within the deposition chamber. Turning on the electrical field leads to a further decrease of the particles passing through the chamber. Figure $4 \mathrm{~b}$ displays the size dependence of the fraction of particles deposited when the electrical field is on, relative to the particle number passing through the chamber without electrical field. This is calculated from four SMPS scans, and the resulting standard deviations are shown as error bars. Due to low counting statistics at larger diameters, the error increases strongly with increasing diameter. The smallest particles $(<20 \mathrm{~nm})$ are deposited with an efficiency of about $15 \%, 40-120 \mathrm{~nm}$ particles with about $40-45 \%$ efficiency, and particles larger than $120 \mathrm{~nm}$ with about $30 \%$ efficiency. Over a wide particle size range, the particle deposition efficiency is only weakly dependent on the particle diameter, which can be explained by the different deposition processes for small and large particles, i.e., diffusional processes for small particles and impaction for large particles as described in detail by Savi and co-workers. ${ }^{(15)}$

In terms of particle mass concentration, $41 \%$ of the aerosol passes the deposition chamber with the electrical field off and $22 \%$ with the electrical field on, relative to the bypass mode (black distribution in Fig. 4a). Thus, on a mass basis, $19 \%$ of the particles entering the deposition chamber are deposited in the chamber due to the electrical field. However, these measurements do not allow verifying whether all
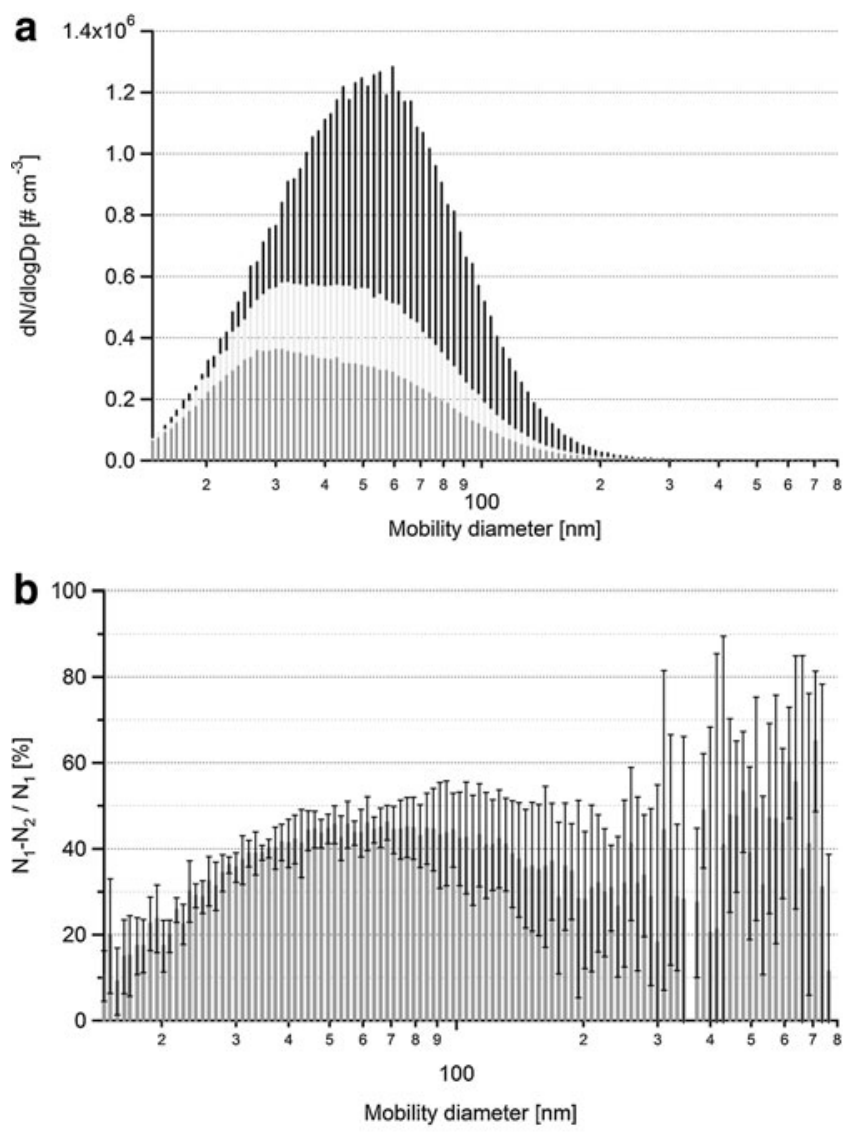

FIG. 4. Size-dependent deposition of particles in the deposition chamber. (a) Size distribution of particles bypassing the deposition chamber (black), passing through the deposition chamber without electrical field (light gray), and passing through the deposition chamber with electrical field (gray). (b) Size-dependent particle fraction deposited in the deposition chamber due to the electrical field. The $y$-axis denotes the relation $\left(N_{1}-N_{2}\right) / N_{1}$ in percent, where $N_{1}$ is the mean value of $\mathrm{d} N / \mathrm{d} \log D_{\mathrm{p}}$ of four SMPS scans without electrical field and $N_{2}$ the analogous value with electrical field. The error bars represent the corresponding standard deviations.

these particles are actually deposited on the cell cultures. This was determined in more detail with the IC/MS method described below.

Particle deposition efficiency on the cell cultures. For a detailed quantification of the particles deposited on the cell cultures, six different experiments were performed (see Table 1). In these experiments, adipic acid particles were quantified using IC/MS. The variability of the deposition was determined for two different plates (experiments 1-4, Table 1). These data were compared with particle deposition without an electric field (experiment 6) and an experiment where adipic acid was quantified in the wells and on the counter electrode, i.e., the mesh of the delivery tubes (experiment 5).

Table 2 lists the results of these experiments. Numbers are given as fractions of the adipic acid mass deposited relative to the adipic acid mass entering the deposition chamber (in percent). Figure 5 shows the average deposition efficiencies of experiments 1-5 for every well of the plates. The left $y$-axis shows the fraction of deposited particle mass in percent. An 
Table 1. Overview of Particle Deposition Experiments Analyzed with IC/MS

\begin{tabular}{lllll}
\hline & Experiments $1 \mathcal{E} 2$ & Experiments 3 E 4 & Experiment 5 & Experiment 6 \\
\hline E-field frequency & $1 \mathrm{~Hz}$ & $1 \mathrm{~Hz}$ & $1 / 3 \mathrm{~Hz}$ & No field \\
12-well plate number & 1 & 2 & 1 All wells, all meshes & 4 wells, 4 meshes \\
IC/MS analysis & All wells & All wells & All &
\end{tabular}

average deposition efficiency of $8.4 \%$ with a relative standard deviation of $24 \%$ is observed. The average particle deposition efficiency was $7.6 \% \quad(21 \%$ relative standard deviation) onto plate 1 (average of experiments 1, 2, and 5) and $9.8 \%$ (19\% relative standard deviation; see Table 2$)$ onto plate 2 (average of experiments 3 and 4). The difference is likely due to slight variation in the machining of the two plates where the distance between the end of the delivery tubes and the wells is a critical parameter. The average wellto-well variability of the deposition efficiency is $15.6 \%$ (i.e., average of the standard deviations of all wells in experiments $1-5$; see Table 2) with a standard deviation of $24.7 \%$.

The right $y$-axis in Figure 5 shows the fraction of particle mass deposited, considering only the charged particles. The mode of the adipic acid particles is about $50 \mathrm{~nm}$ (Fig. 4a), and the corresponding mass median diameter (MMD) is about $100 \mathrm{~nm}$. According to Wiedensohler, ${ }^{(20)}$ about $28.5 \%$ of $100-$ nm particles carry a positive and $28.5 \%$ a negative charge at equilibrium. Thus, about $71.5 \%$ are neutral or carry a charge with the opposite polarity, and therefore are not deposited on the inserts due to the electrical field. This means that about $24 \%$ of all charged particles are deposited in plate 1 and about $34 \%$ in plate 2 .

A decreased frequency of switching between positive and negative polarity could potentially increase the deposition efficiency (see Fig. 3 in Savi et al. ${ }^{(15)}$ ). Therefore, in experiment 5 (Table 2), the frequency was lowered to $1 / 3 \mathrm{~Hz}$ compared with $1 \mathrm{~Hz}$ (experiments 1-4). No statistically significant increased deposition could be observed, indicating that for the geometry of the deposition chamber, $1 \mathrm{~Hz}$ is an optimal value.

Particle deposition decreased significantly to about $2.7 \%$ when no electrical field was applied (experiment 6), showing that the electrical field increases the deposition efficiency by about a factor of 3.1 compared with deposition by diffusion processes (i.e., with the electrical field off) for particles with $100 \mathrm{~nm}$ MMD.

Due to the ${ }^{85} \mathrm{Kr}$ bipolar charger, particles are charged positively and negatively, which mimics the charge distribution present in the atmosphere. However, this also results in a limited deposition efficiency on the cell cultures, because only particles of one polarity are attracted to the cell cultures, whereas particles of the other polarity are attracted to the counter electrode, i.e., the metal meshes at the end of the delivery tubes. This can be clearly seen in experiment 5 where the adipic acid concentration was measured in the wells and on the meshes at the end of the delivery tubes. On average, about $35 \%$ more particles were deposited on the meshes $(12.2 \pm 2.0 \%)$ compared with the wells $(8.8 \pm 1.3 \%)$. The combined deposition efficiency on the meshes and the wells is $21 \%$ $( \pm 2 \%)$ and includes particles deposited due to the electrical field, but also particles that are deposited due to diffusional/ turbulent processes. As described above, about 57\% of all 100$\mathrm{nm}$ particles are charged using a bipolar charger. Assuming that about half of the particles are lost in the chamber (see Fig. 6 below) and assuming that these losses affect neutral and charged particles equally, about $74 \%$ of the charged particles

Table 2. Deposition Efficiencies from all IC/MS Measurements

\begin{tabular}{|c|c|c|c|c|c|c|c|c|c|c|c|c|c|}
\hline & Exp. 1 & Exp. 2 & Exp. 3 & Exp. 4 & Exp. 5 & Exp. 5 & Exp. 5 & Exp. 6 & Exp. 6 & \multicolumn{2}{|c|}{ Exp. $1 \mathcal{E} 2$} & \multicolumn{2}{|c|}{ Exp. $3 \mathcal{E} 4$} \\
\hline $\begin{array}{l}\text { Well/ } \\
\text { mesh \# }\end{array}$ & $\begin{array}{c}\text { Well } \\
1 \mathrm{~Hz} \\
\text { Plate } 1\end{array}$ & $\begin{array}{c}\text { Well } \\
1 \mathrm{~Hz} \\
\text { Plate } 1\end{array}$ & $\begin{array}{c}\text { Well } \\
1 \mathrm{~Hz} \\
\text { Plate } 2\end{array}$ & $\begin{array}{c}\text { Well } \\
1 \mathrm{~Hz} \\
\text { Plate } 2\end{array}$ & $\begin{array}{c}\text { Well } \\
\text { 1/3 Hz } \\
\text { Plate } 1\end{array}$ & $\begin{array}{l}\text { Mesh } \\
\text { 1/3 Hz } \\
\text { Plate } 1\end{array}$ & Well + mesh & $\begin{array}{c}\text { Well } \\
\text { No field } \\
\text { Plate } 1\end{array}$ & $\begin{array}{c}\text { Mesh } \\
\text { No field } \\
\text { Plate } 1\end{array}$ & Average & $\begin{array}{c}\% \text { of } \\
\text { charged } \\
\text { particles }\end{array}$ & Average & $\begin{array}{c}\% \text { of } \\
\text { charged } \\
\text { particles }\end{array}$ \\
\hline 1 & 6.4 & 7.0 & 12.3 & 6.7 & 6.8 & 11.0 & 17.7 & 3.2 & 2.5 & 6.7 & 23.4 & 9.5 & 33.1 \\
\hline 2 & 4.8 & 5.6 & 10.9 & 6.8 & 9.5 & 10.9 & 20.4 & - & - & 5.2 & 18.3 & 8.9 & 31.0 \\
\hline 3 & 6.5 & 6.2 & 12.1 & 7.7 & 7.5 & 12.5 & 20.1 & - & - & 6.4 & 22.3 & 9.9 & 34.6 \\
\hline 4 & 6.6 & 5.7 & 10.8 & 8.7 & 8.9 & 12.0 & 20.9 & 2.2 & 2.3 & 6.2 & 21.6 & 9.7 & 34.1 \\
\hline 5 & 6.7 & 6.1 & 14.1 & 8.8 & 8.8 & 12.3 & 21.1 & - & - & 6.4 & 22.2 & 11.4 & 40.0 \\
\hline 6 & 7.9 & 5.8 & 10.5 & 8.8 & 9.2 & 11.9 & 21.1 & - & - & 6.9 & 24.1 & 9.6 & 33.7 \\
\hline 7 & 7.2 & 4.4 & 8.9 & 8.7 & 8.2 & 10.6 & 18.8 & - & - & 5.8 & 20.3 & 8.8 & 30.9 \\
\hline 8 & 7.8 & - & 9.4 & - & 9.7 & 9.2 & 18.9 & 3.7 & 1.7 & 7.8 & 27.3 & 9.4 & 32.9 \\
\hline 9 & 7.9 & 5.6 & 9.5 & 8.2 & 6.9 & 10.7 & 17.6 & - & - & 6.8 & 23.7 & 8.9 & 31.1 \\
\hline 10 & 7.0 & 8.8 & 11.2 & 9.1 & 8.9 & 13.7 & 22.6 & - & - & 7.9 & 27.7 & 10.1 & 35.5 \\
\hline 11 & 9.8 & 7.3 & 11.4 & 9.0 & 9.8 & 14.9 & 24.6 & - & - & 8.5 & 29.9 & 10.2 & 35.7 \\
\hline 12 & 9.9 & 8.3 & 12.1 & 9.0 & 11.3 & 16.4 & 27.7 & 1.7 & 2.3 & 9.1 & 31.9 & 10.5 & 36.8 \\
\hline Mean & 7.4 & 6.4 & 11.1 & 8.3 & 8.8 & 12.2 & 21.0 & 2.7 & 2.2 & 7.0 & 24.4 & 9.8 & 34.1 \\
\hline $\mathrm{SD}$ & 1.4 & 1.3 & 1.4 & 0.9 & 1.3 & 2.0 & 2.9 & 0.9 & 0.3 & & & & \\
\hline SD (\%) & 19 & 20 & 13 & 11 & 15 & 16 & 14 & 34 & 15 & & & & \\
\hline
\end{tabular}

Fraction of particles deposited on wells and on metal meshes at the end of the delivery tubes. Numbers are given in percent relative to the total particle mass entering the deposition chamber. The fraction of charged particles is calculated for a mode diameter of $100 \mathrm{~nm}$ and assuming that $28.5 \%$ of all particles are either positively or negatively charged. ${ }^{(20)}$ For experiment 6 , only four wells were analyzed. Plates 1 and 2 refer to two different 12-well plates used to hold the cell culture inserts (see Fig. 1 for details). 


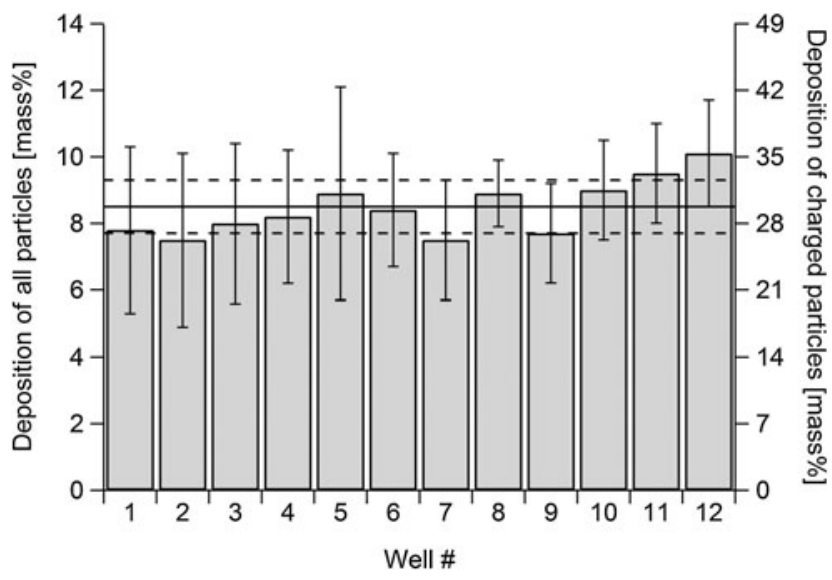

FIG. 5. Deposition efficiency of 100-nm aerosol particles (MMD) in each well. Each column represents the average value of the five experiments (experiments 1-5) performed with the two different 12-well plates (nos. 1 and 2; see Tables 1 and 2). The error bars are \pm one standard deviation. The solid line indicates the averaged particle deposition efficiency on all 12 wells, and the dashed lines illustrate the corresponding standard deviation. On average, $8.4 \pm 0.8 \%$ (mass) of all particles or $30 \pm 2.9 \%$ (mass) of the charged particles are deposited on the wells.

( $21 \%$ divided by $28.5 \%$ ) are deposited in the wells and on the meshes due to the electrical field applied.

Figure 6 summarizes and compares the results from SMPS and IC/MS measurements. The left bar is derived from SMPS mass concentration measurements without electrical field where $41 \%$ of the particle mass passes the deposition chamber (light gray fraction) and 59\% is deposited in the instrument. From the IC/MS measurements, we know that about $5 \%$ of the particles deposit on the meshes and in the wells if no electrical field is applied (experiment 6). This fraction is represented by the white part of the bar, and thus about $54 \%$ are lost in other parts of the instrument.

The middle bar shows the SMPS measurements with the electrical field applied. Here only $22 \%$ of the particles exit the chamber. As the overall diffusional losses in the deposition

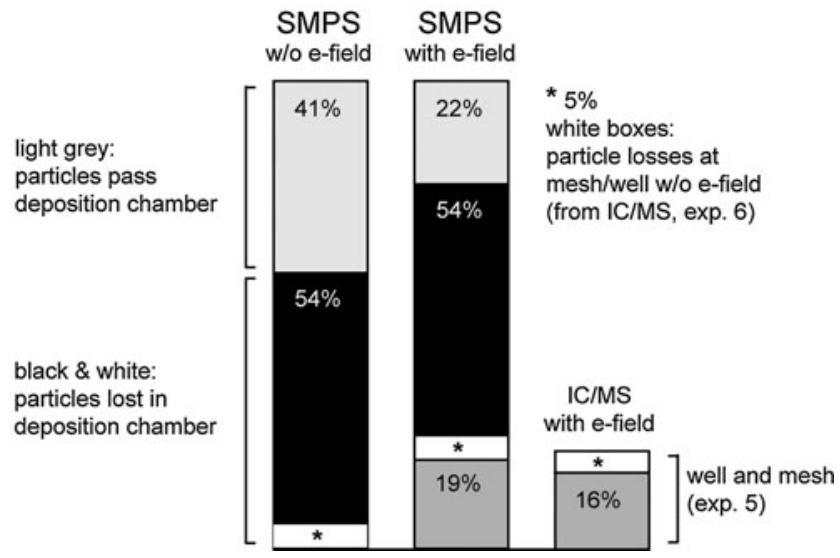

FIG. 6. Comparison of particle deposition methods. Particle deposition within the deposition chamber with and without electrical field applied using two different techniques, i.e., SMPS and IC/MS. See text for details. chamber are assumed to be the same as for conditions without electrical field, i.e., $59 \%$, about $19 \%$ are deposited on the wells and the meshes due to the effect of the electrical field (gray fraction).

The right bar shows the particles deposited as quantified with the IC/MS technique (experiment 5). Twenty-one percent of the particle mass is deposited on the meshes and the wells. Diffusional deposition is assumed to account again for $5 \%$, resulting in $16 \%$ of the particles deposited due to the electrical field, which compares well with the 19\% determined from the SMPS experiment (middle bar).

Higher total deposition efficiencies could be reached with a unipolar charging of the particles as shown by others. ${ }^{(21-23)}$ De Bruijne et al. ${ }^{(21)}$ report a deposition efficiency of 35-47\%, whereas Sillanpää et al. ${ }^{(23)}$ reached even $95 \%$. Lenz et al. ${ }^{(22)}$ determined a deposition efficiency of $7.2 \%$ for a deposition chamber, which was developed to investigate the deposition of nanoparticles in liquids.

\section{Conclusions}

We developed and characterized a new instrument to deposit aerosol particles onto cell cultures. Within the deposition chamber, aerosol particles are deposited on cell cultures directly out of a continuous aerosol flow at realistic physiological conditions, i.e., at $36-37^{\circ} \mathrm{C}$ and $90-95 \% \mathrm{RH}$. This tool can be used to investigate the impact of atmospheric, engineered, as well as therapeutic aerosols on cell cultures. Twelve cell cultures can be exposed simultaneously, allowing for a larger number of exposures compared with our previous instrument ${ }^{(15)}$ and other systems described in the literature where four or less cell cultures are exposed simultaneously. ${ }^{(21,23)}$ The new deposition chamber is a compact and portable system allowing for particle sampling at any aerosol source, even outside a cell biology or particle laboratory.

A key feature of the deposition chamber is the efficient electrostatic particle deposition on the cell cultures using bipolarly charged aerosol particles, which mimics the charge distribution of particles in the ambient atmosphere. ${ }^{(24)}$ About $24-34 \%$ of all charged particles are deposited on the cell cultures, which is about a factor of 3-4 larger than deposition solely due to diffusional processes for the 100-nm particles (MMD) (sigma 1.7) used in this study (which is a typical size for ambient atmospheric aerosol particles). It is expected that this factor is even more favorable for larger particles, where diffusional deposition is less efficient. Deposition of particles of both polarities assures that, on average, no net charge is deposited on the cells. However, bipolar charging has the disadvantage that a fraction of the particles always carries no net charge and is thus not efficiently deposited in our chamber. The fraction of charged particles is mainly a function of particle size and varies between about $20 \%$ (one polarity) for $50-\mathrm{nm}$ particles and about $45 \%$ for $1,000-\mathrm{nm}$ particles. ${ }^{(20)}$

The two analytical methods applied in this study to quantify the deposition efficiency of particles within the deposition chamber are in good agreement. The variability of the deposition efficiency between the 12 cell culture wells was assessed to be between $10 \%$ and $20 \%$.

\section{Acknowledgments}

This study was financially supported by Swiss National Science Foundation grant no. K-32K1-120524. The authors 
thank their colleagues G. Wehrle, K. Baumgartner, and $\mathrm{H}$. Benz for their competent technical advice. We thank $\mathrm{H}$. Burtscher for very valuable discussions. P.M. performed the deposition chamber characterization studies and contributed to the draft of the manuscript. A.P.P., L.K., and E.W. contributed to the chamber characterization studies. J.D. and U.B. designed and supervised the characterization studies and contributed to the draft of the manuscript. J.R. and M.F. contributed to the design of the chamber. M.G. and M.K. contributed to the design and the characterization studies of the chamber and to the draft of the manuscript. All authors read and approved the final manuscript.

\section{Author Disclosure Statement}

All authors declare that no conflicts of interest exist.

\section{References}

1. Geiser M, and Kreyling WG: Deposition and biokinetics of inhaled nanoparticles. Part Fibre Toxicol. 2010;7:2.

2. Laden F, Schwartz J, Speizer FE, and Dockery DW: Reduction in fine particulate air pollution and mortality-extended follow-up of the Harvard six cities study. Am J Respir Crit Care Med. 2006;173:667-672.

3. Pope CA, Hansen ML, Long RW, Nielsen KR, Eatough NL, Wilson WE, and Eatough DJ: Ambient particulate air pollution, heart rate variability, and blood markers of inflammation in a panel of elderly subjects. Environ Health Perspect. 2004;112:339-345.

4. Schulz H, Harder V, Ibald-Mulli A, Khandoga A, Koenig W, Krombach F, Radykewicz R, Stampfl A, Thorand B, and Peters A: Cardiovascular effects of fine and ultrafine particles. J Aerosol Med. 2005;18:1-22.

5. Delfino RJ, Sioutas C, and Malik S: Potential role of ultrafine particles in associations between airborne particle mass and cardiovascular health. Environ Health Perspect. 2005;113: 934-946.

6. Peters A, Dockery DW, Heinrich J, and Wichmann HE: Shortterm effects of particulate air pollution on respiratory morbidity in asthmatic children. Eur Resp J. 1997;10:872-879.

7. Wichmann HE, Spix C, Tuch T, Wölke G, Peters A, Heinrich J, Kreyling WG, and Heyder J: Daily mortality and fine and ultrafine particles in Erfurt, Germany, part I: role of particle number and particle mass. Res Rep Health Eff Inst. 2000;(98):5-86; discussion 87-94.

8. Kreyling WG, Tuch T, Peters A, Pitz M, Heinrich J, Stolzel M, Cyrys J, Heyder J, and Wichmann HE: Diverging long-term trends in ambient urban particle mass and number concentrations associated with emission changes caused by the German unification. Atmos Environ. 2003;37:3841-3848.

9. Maynard AD: Nanotechnology: assessing the risks. Nano Today. 2006;1:22-33.

10. Warheit DB, Laurence BR, Reed KL, Roach DH, Reynolds GAM, and Webb TR: Comparative pulmonary toxicity assessment of single-wall carbon nanotubes in rats. Toxicol Sci. 2004;77:117-125.

11. Zhang QW, Kusaka Y, Zhu XQ, Sato K, Mo YQ, Kluz T, and Donaldson K: Comparative toxicity of standard nickel and ultrafine nickel in lung after intratracheal instillation. J Occup Health. 2003;45:23-30.

12. Zhou YM, Zhong CY, Kennedy IM, Leppert VJ, and Pinkerton KE: Oxidative stress and $\mathrm{NF} \kappa \mathrm{B}$ activation in the lungs of rats: a synergistic interaction between soot and iron particles. Toxicol Appl Pharmacol. 2003;190:157-169.
13. Sporty JL, Horálková L, and Ehrhardt C: In vitro cell culture models for the assessment of pulmonary drug disposition. Expert Opin Drug Metab Toxicol. 2008;4:333-345.

14. Steimer A, Haltner E, and Lehr CM: Cell culture models of the respiratory tract relevant to pulmonary drug delivery. J Aerosol Med. 2005;18:137-182.

15. Savi M, Kalberer M, Lang D, Ryser M, Fierz M, Gaschen A, Ricka J, and Geiser M: A novel exposure system for the efficient and controlled deposition of aerosol particles onto cell cultures. Environ Sci Technol. 2008;42:56675674.

16. Parsons MT, Mak J, Lipetz SR, and Bertram AK: Deliquescence of malonic, succinic, glutaric, and adipic acid particles. J Geophys Res. 2004;109:D06212.

17. Bilde M, Svenningsson B, Monster J, and Rosenorn T: Evenodd alternation of evaporation rates and vapor pressures of $\mathrm{C}_{3}-\mathrm{C}_{9}$ dicarboxylic acid aerosols. Environ Sci Technol. 2003; 37:1371-1378.

18. McRae RDR, Jones AS, Young P, and Hamilton J: Resistance, humidity and temperature of the tracheal airway. Clin Otolaryngol. 1995;20:355-356.

19. Gaschen A, Lang D, Kalberer M, Savi M, Geiser T, Gazdhar A, Lehr CM, Bur M, Dommen J, Baltensperger U, and Geiser M: Cellular responses after exposure of lung cell cultures to secondary organic aerosol particles. Environ Sci Technol. 2010;44:1424-1430.

20. Wiedensohler A: An approximation of the bipolar chargedistribution for particles in the sub-micron size range. J Aerosol Sci. 1988;19:387-389.

21. de Bruijne K, Ebersviller S, Sexton KG, Lake S, Leith D, Goodman R, Jetters J, Walters GW, Doyle-Eisele M, Woodside $\mathrm{R}$, Jeffries HE, and Jaspers I: Design and testing of Electrostatic Aerosol In Vitro Exposure System (EAVES): an alternative exposure system for particles. Inhal Toxicol. 2009; 21:91-101.

22. Lenz A, Karg E, Lentner B, Dittrich V, Brandenberger C, Rothen-Rutishauser B, Schulz H, Ferron G, and Schmid O: A dose-controlled system for air-liquid interface cell exposure and application to zinc oxide nanoparticles. Part Fibre Toxicol. 2009;6:32.

23. Sillanpää M, Geller MD, Phuleria HC, and Sioutas C: High collection efficiency electrostatic precipitator for in vitro cell exposure to concentrated ambient particulate matter (PM). J Aerosol Sci. 2008;39:335-347.

24. Hinds WC: Aerosol Technology: Properties, Behavior, and Measurement of Airborne Particles. John Wiley \& Sons, New York; 1982.

Received on May 17, 2012 in final form, September 24, 2012

Reviewed by: Carsten Ehrhardt Otmar Schmid Carsten Schleh

Address correspondence to: Dr. Markus Kalberer University of Cambridge Department of Chemistry Center for Atmospheric Sciences Lensfield Road, Cambridge, CB2 1EW, UK

E-mail: markus.kalberer@atm.ch.cam.ac.uk 